\title{
Assessing the Suitability of Agricultural Practices in the Faria Catchment, Palestine Based on the Agricultural Groundwater Vulnerability Map
}

\author{
Abboushi $\mathrm{A}^{1 *}$, Shadeed $\mathrm{S}^{2}$ and Almasri $\mathrm{M}^{3}$ \\ ${ }^{1}$ Dubai Municipality, Government of Dubai, UAE \\ ${ }^{2}$ Water and Environmental Studies Institute, An-Najah National University, Palestine \\ ${ }^{3}$ Civil Engineering Department, An-Najah National University, Palestine \\ *Corresponding author: Atta Abboushi, Dubai Municipality, Government of Dubai, \\ Dubai, UAE, Tel: 00971525687203; Email: maher-aboushi@hotmail.com
}

Review Article

Volume 3 Issue 3

Received Date: June 30, 2019

Published Date: July 23, 2019

DOI: $10.23880 /$ jenr-16000166

\section{Abstract}

This study aimed to decide on the on-ground agricultural suitability mainly for the agricultural areas in Faria catchment, based on agricultural groundwater vulnerability mapping. Where, Faria agricultural catchment is a $320 \mathrm{Km}^{2}$, located in the north-eastern part of the West Bank, Palestine. Agricultural suitability, focused on the suitability of the agricultural on-ground activities which are currently practiced in the catchment and their potential impacts on the groundwater quality deterioration. The available agricultural groundwater vulnerability map of Faria was used to assess the agricultural suitability in the catchment's agricultural areas. Results indicate that the moderate and high groundwater vulnerable agricultural areas form about $74 \%$ of the total agricultural areas in the catchment. This requires a dire need to monitor and manage the uncontrolled agricultural practices in these areas. Thus, the obtained statistical measures were employed to introduce some agricultural management practices to maximize both the environmental and socio-economic conditions in the catchment.

Keywords: Faria Catchment; West Bank; Palestine; Groundwater Vulnerability; Agricultural Suitability; Groundwater Quality Deterioration; Uncontrolled Agricultural Practices; Agricultural Management Practices; Socio-Economic Conditions

\section{Objectives}

The followings are the main objectives of this research study:

- To develop an interaction map of the existing agricultural areas and the available agricultural groundwater vulnerability map of the Faria catchment.
- To link the concept of on-ground agricultural suitability with the developed groundwater vulnerability map in the catchment.

- To introduce some preliminary agro-management options/practices to preserve groundwater quality in the catchment, depending on the existing groundwater vulnerability map. 


\section{Methodology}

The overall methodology of this research study is depicted in Figure 1.

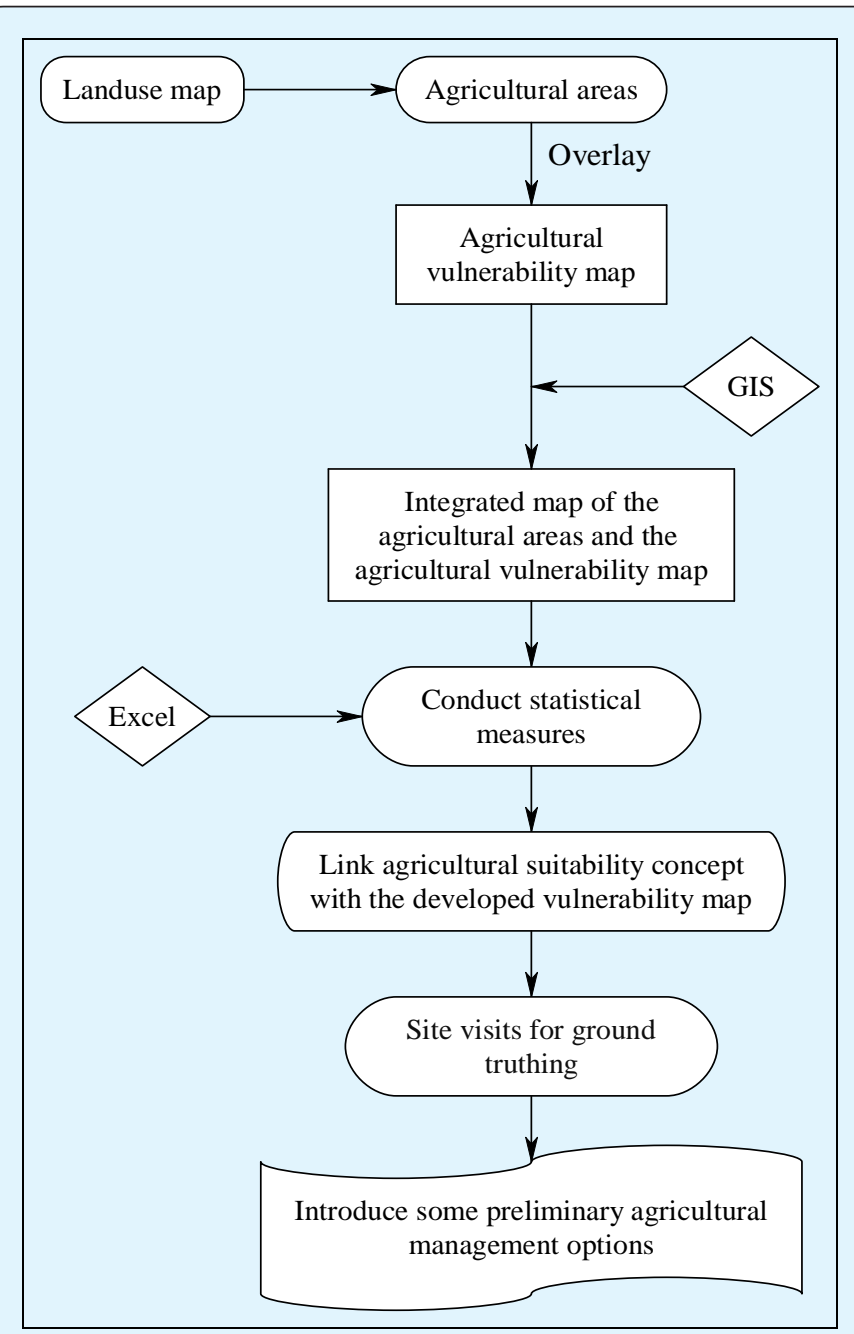

Figure 1: General conceptual methodology.

The main concept here is to intersect the agricultural areas and the groundwater agricultural vulnerability map of Faria in order to identify the different vulnerable zones within those areas. After that, some statistical measures were conducted to quantify the desired intersection. Then, the agricultural suitability concept was applied to introduce some preliminary agro-management options. This aims to minimize the potential negative impacts of the uncontrolled agricultural activities on the groundwater quality, and maximize the socio-economic conditions in the catchment [1].

\section{Results, Analysis, and Discussion}

In order to assess the suitability of the agricultural practices to the quality of the groundwater aquifers in the Faria catchment, the agricultural areas which are dominated by supplementary irrigated agriculture Shadeed [2] were identified and intersected with the available groundwater agricultural vulnerability map Figure 2. Then, an integrated vulnerability map was obtained by utilization of the GIS capabilities in geoprocessing, as shown in Figure 3 [3]. Also, the spatial distribution of the wells and springs and the path of the main Wadi (which are considered the main irrigation sources in the catchment) are shown in the same figure.

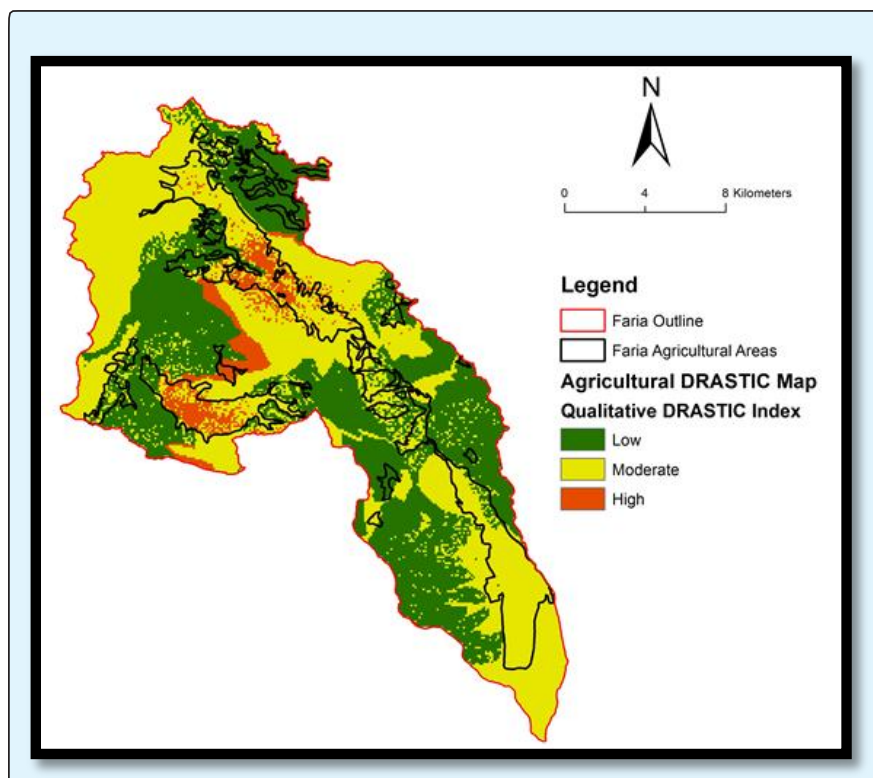

Figure 2: Overlaying the agricultural areas on the agricultural vulnerability map.

From the above figure, it can be concluded that most of the highly groundwater vulnerable zones are located within the agricultural areas in the Faria catchment. This means that the uncontrolled agricultural practices that are taking place in these areas may pose serious adverse consequences on the groundwater quality [4]. Also, it can be noted Figure 3 that most of the wells were drilled in the agricultural areas and so they have high potential to be polluted by the uncontrolled agricultural activities through the surface infiltration [5]. 


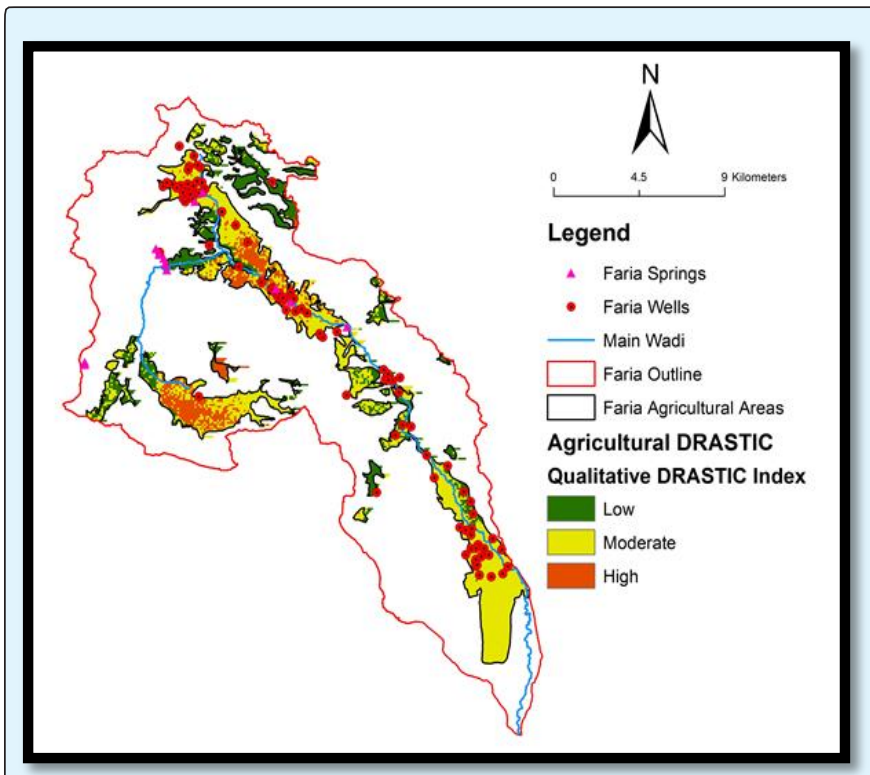

Figure 3: The integrated map of the agricultural areas and the agricultural vulnerability map in the Faria catchment.

Also, it is important to mention that the frequent field visits to the catchment revealed that many farmers are being used polluted Wadi flow to irrigate their farms directly and without any preliminary treatment [1] Figure 4. This in turn will not only affect the agricultural products, but also may affect the groundwater quality especially beneath highly groundwater vulnerable areas [5].

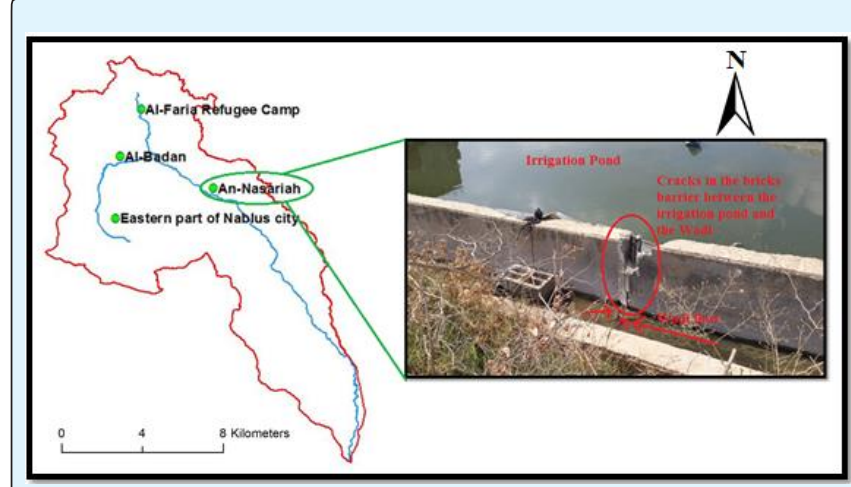

Figure 4: The Wadi flow discharges to an irrigation pond through intentionally-made cracks in the bricks barrier.
The integrated developed map was also utilized in computing the percentages of the agricultural areas occupied by each descriptive agricultural vulnerability index Figure 5.

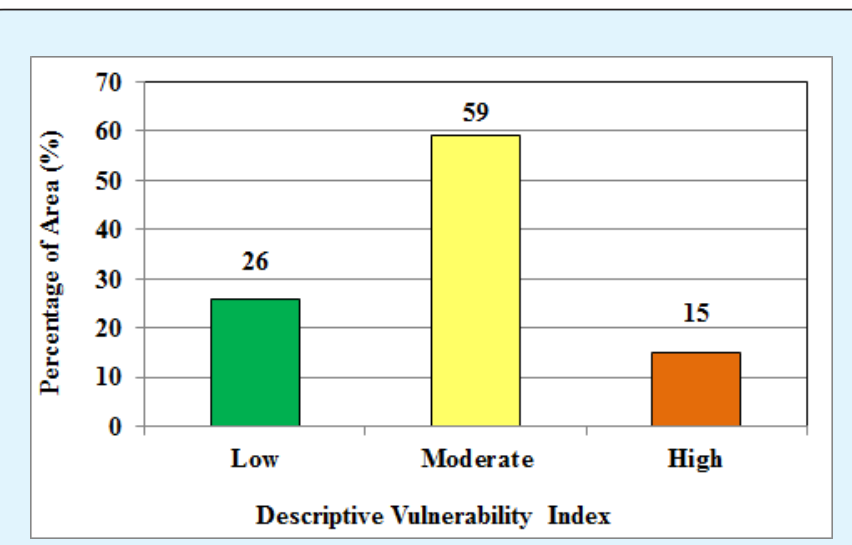

Figure 5: The overall percentage of the agricultural areas occupied by each descriptive vulnerability index of the agricultural integrated vulnerability map.

Figure 5 shows that the moderate vulnerable zone occupies the highest percentage of the agricultural areas in the Faria catchment. On the other hand, the percentages of the agricultural areas which are occupied by both the low and high vulnerable zones are $26 \%$ and $15 \%$ respectively. Also, it is noted that the moderate and high vulnerable agricultural areas form $74 \%$ of the total agricultural areas in the Faria catchment. This in turn requires a special and careful attention in the management of the agricultural practices in those areas.

\section{Introducing Some Preliminary Agro- Management Options/Practices}

In light of the above, some preliminary agromanagement options/practices could be concluded and readily implemented in the agricultural areas of the Faria catchment, such that groundwater quality is secured while socio-economic conditions are intensified. Such of these management options may include but not limited to: a) The agricultural practices should be controlled, monitored, and managed in the moderately vulnerable zones, and with higher priority in the highly vulnerable zones of the agricultural areas in the catchment. Thus, nutrients, agro-chemicals, and manures should be wisely used [6]. 


\section{Journal of Ecology \& Natural Resources}

b) Some of agricultural practices should be totally prohibited (e.g. excessive use of toxic and persistent pesticides) especially in the highly vulnerable zones of the agricultural areas in the catchment [6].

c) Irrigation water management includes efficient irrigation system and proper irrigation scheduling should be used. Hence, leaching of soluble salts and pesticides to groundwater through the soil profile will be reduced [7]. Additionally, agricultural return flow to the main Wadi will be minimized [4]. Eventually, the groundwater quality will be improved.

d) The common use of untreated wastewater flowing in the main Wadi for agricultural purposes should be halted [8]. Monitoring programs and public awareness campaigns should be lunched to deal with any relevant negative environmental consequences and violations.

e) Soil erosion and the associated potential transport of agro-chemicals should be controlled in the agricultural areas [9], especially in the vicinity to the main Wadi. The use of terraces, contour plowing, and ground cover could be practiced to minimize soil erosion [10].

\section{References}

1. Abboushi A, Shadeed S, and Almasri M (2015a) Development of Agricultural Best Management Practices to Preserve Groundwater Quality in the Faria Catchment, Palestine, Unpublished technical report, Water and Environmental Studies Institute and An-Najah National University, Nablus, Palestine.

2. Shadeed S (2008) Up to Date Hydrological Modeling in Arid and Semi-Arid Catchment, the Case of Faria Catchment, West Bank, Palestine, PhD. dissertation, Faculty of Forest and Environmental Sciences, AlbertLudwigs-Universität, Freiburg imBreisgau, Germany.

3. Abboushi A, Shadeed S, Almasri M (2014) Assessing and Mapping of Groundwater Vulnerability to
Contamination Using GIS-based DRASTIC Method in Faria Catchment, Palestine, Unpublished technical report, Water and Environmental Studies Institute and An-Najah National University, Nablus, Palestine.

4. Abboushi A (2013) A Preliminary Investigation of Wadi-Aquifer Interaction in Semi-Arid Regions: The Case of Faria Catchment, Palestine, Thesis (Msc), AnNajah National University, Nablus, Palestine.

5. Abboushi A, Almasri M, Shadeed S (2015b) A Preliminary Investigation of Wadi-Aquifer Interaction in the Semi-Arid Watershed of Faria, Palestine using Tracer-Based Methodology. Env Earth Sci J 73(12): 7861-7872.

6. Abdullah D (2014) Evaluation of the Impacts of Uncontrolled Agricultural Practices on Soil and Water Resources on the Faria Catchment, Thesis (Msc), AnNajah National University, Nablus, Palestine.

7. Afrous A (2010) Nitrate Leaching in Various Irrigation Methods and Simulating Nitrate Movement and Transport with LEACHN Model, Toward Sustainable Groundwater in Agriculture, California, USA.

8. Shadeed S, Abboushi A, Almasri M (2017) Developing a GIS-Based Agro-Land Suitability Map for the Faria Agricultural Catchment, Palestine. Int J Global Env Issues 16(1-3): 190-204.

9. Morgan L (2005) Critical Aquifer Recharge Areas, Guidance Document, Washington State Department of Ecology, Olympia, WA, USA.

10. Food and Agricultural Organization of the United Nations (FAO) (1993) Soil Tillage in Africa: Needs and Challenges, Rome, Italy. 